\title{
Práticas de aprendizagens integradoras no Ensino Superior como um direito de todos: análise das experiências de inclusáo nos cursos de Psicologia na perspectiva da teoria da complexidade e da transdisciplinaridade
}

\author{
Idenise Naiara Lima Soares ${ }^{1}$ \\ https://orcid.org/0000-0003-1819-8839 \\ Maria Dolores Fortes Alves ${ }^{2}$ \\ https://orcid.org/0000-0002-2292-8518
}

\section{Resumo}

A pesquisa explicitada neste artigo teve como objetivo geral investigar as práticas pedagógicas desenvolvidas no curso de psicologia ofertado na Universidade Federal de Alagoas (UFAL) e suas aproximaçóes com as Práticas de Aprendizagem Integradoras trazidas por Alves (2016) que contribuem para um processo inclusivo que compreenda o sujeito para além de sua dimensão cognitiva. Metodologicamente tratou-se de uma pesquisa de natureza qualitativa do tipo exploratória. Como instrumento de coleta de dados utilizou-se a entrevista estruturada no qual foi aplicada com os professores de psicologia da UFAL. Os dados foram tratados com fundamento no arcabouço da análise de conteúdo e interpretado sob a luz do referencial teórico da complexidade, da transdisciplinaridade e das práticas de aprendizagens integradoras e inclusivas (PAII). Os conteúdos emergentes nas falas dos sujeitos da pesquisa se aproximam das PAII, visto que compartilham da percepção do sujeito para além de uma única dimensão. Apesar disso, nota-se a necessidade de ampliar estudos que se voltem para essa temática. Por fim, percebemos a abertura dos profissionais entrevistados para conhecer novas formas de ensinar e aprender utilizando a criatividade como subsídio fundamental na construçáo do conhecimento. Isso nos permite pensar sobre a existência de uma dedicação para realizar práticas pedagógicas as quais superam as estratégias tradicionais de ensino.

Palavras-chave: Complexidade, Transdisciplinaridade, Práticas de aprendizagens integradoras, Inclusão.

\footnotetext{
${ }^{1}$ Mestre em Educação, Universidade Federal de Alagoas, Maceió, AL. idenisepsi@gmail.com.

2 Professora Doutora, Universidade Federal de Alagoas, Maceió, AL. mdfortes@gmail.com.
} 


\title{
Integrative learning practices in higher education as a right for all: analysis of experiences of inclusion in Psychology courses from the perspective of complexity theory and transdisciplinarity
}

\begin{abstract}
The research explained in this article had the general objective of investigating the pedagogical practices developed in the psychology course offered at the Federal University of Alagoas (UFAL) and its approximations with the Integrative Learning Practices brought by Alves (2016) that contribute to an inclusive process that understands the subject beyond its cognitive dimension. Methodologically, it was a qualitative research of the exploratory type. As a data collection instrument, the structured interview was used in which it was applied with psychology professors at UFAL. The data were treated based on the content analysis framework and interpreted in the light of the theoretical framework of complexity, transdisciplinarity and integrative and inclusive learning practices (PAII). The contents emerging in the speeches of the research subjects are close to the PAII, since they share the subject's perception beyond a single dimension. Despite this, there is a need to expand studies that focus on this topic. Finally, we perceive the openness of the interviewed professionals to discover new ways of teaching and learning using creativity as a fundamental subsidy in the construction of knowledge. This allows us to think about the existence of a dedication to carry out pedagogical practices that surpass traditional teaching strategies.
\end{abstract}

Keywords: Complexity, Transdisciplinarity, Integrative learning practices, Inclusion.

\section{Introduçáo}

As "práticas de aprendizagens integradoras e inclusivas" emergem para possibilitar um caminho de favorecer o processo de inclusão em diversos níveis de ensino (ALVES, 2016). Entendemos que estas práticas emergem como uma forma de tentar alcançar uma justiça social. Aqui, trataremos especificamente do olhar para o ensino superior. Este artigo é um recorte da pesquisa de mestrado de Soares (2020) que traz como questáo norteadora: "como a docência nos cursos de Psicologia se aproxima de uma prática inclusiva que compreenda o sujeito para além de sua dimensão cognitiva, considerando-o em sua inteireza?”.

A pesquisa teve por objetivo geral investigar as práticas pedagógicas desenvolvidas no curso de psicologia ofertado na Universidade Federal de Alagoas-UFAL e suas aproximaçóes com as práticas integradoras que contribuem para um processo inclusivo que compreenda o sujeito para além de sua dimensão cognitiva. Para tal, aplicamos um questionário com 10 questóes estruturadas que foram analisadas a luz do referencial teórico da complexidade e da transdisciplinaridade. 
$\mathrm{O}$ arcabouço teórico que embasou o desenvolvimento de toda a pesquisa foram as "Práticas de Aprendizagem Integradoras e Inclusivas (PAII) que tem como base teórico-epistemológica o pensamento complexo, a transdisciplinaridade. Porquanto, como expressa Alves em suas obras, pensar a inclusão pela via da teoria do pensamento complexo é compreender o todo, as partes e a relação entre eles.

\section{As práticas integradoras e inclusivas e as suas contribuiçóes para a inclusão no Ensino Superior}

As pessoas com deficiências enfrentam diariamente dificuldades para almejar seus objetivos educacionais e podem ser impedidos de alcançá-los. Tais dificuldades se apresentam de diversas formas, desde a falta de acessibilidade como os movimentos didáticos engessados realizados pelos professores na tentativa de ensinar seus alunos, como: aulas expositivas onde o professor é o sujeito ativo no processo de ensino e aprendizagem; aulas teóricas que não possibilitam o aluno criar, construir. Tais movimentos baseados numa ciência clássica, fundamentadas em um determinismo absoluto, tende a perdurar até os dias atuais.

A ciência clássica fundamentada pelos princípios da disjunção, redução e determinismo tende a eliminar o acaso, as incertezas. A disjunção trabalha com a separação dos elementos que estão interligados, que não deveriam ser fragmentados em sua natureza. Nesse contexto, não se pode reduzir o conhecimento de um sistema complexo, como o ser humano em formação, as suas partes constituintes de maneira determinista. É necessário compreender que não se pode eliminar as incertezas, é preciso enfrentá-las, pois a imprevisibilidade faz moradia no próprio cerne do determinismo. Com a revolução da mecânica quântica, no início do século XX, emergiu a incerteza lógica, a imprecisão frente às interaçóes de um sistema complexo e a racionalidade passou a não ser mais tão absoluta (MORIN, 2015).

Com base nisso, o ensino para pessoas com deficiências respaldado na ciência clássica determinista reduz o ser humano complexo a apenas uma parte ou dimensão. Isso pode excluí-los, caso, não consigam realizar tarefas esperadas e dependentes de uma determinada dimensão e passam a serem vistos como incapazes. Isso acaba por evidenciar fragilidades numa formação emancipatória, que religa o sujeito as suas diversas potencialidades.

Ao longo da história da educação especial, foram obtidas diferentes formas na tentativa de incluir alunos com deficiências, entretanto algumas 
destas maneiras podem alimentar o processo de exclusão dos sujeitos. Desejar que o discente aprenda conteúdos previstos na matriz curricular, sem compreender como esse sujeito interage com suas potencialidades, com o outro e com o mundo, acaba reduzindo esse sujeito a uma única dimensão, como a cognitiva. O sujeito que não consegue aprender por uma didática, compreendida como eficaz para outros alunos com dificuldades semelhantes a este sujeito, pode ser encarado como um indivíduo incapaz de realizar certas atividades, ficando impedido de desenvolver outras potencialidades. Essa forma de pensar arbitrariamente, também pode ser compreendida como um pensar reducionista, que subjuga o sujeito com deficiência as suas limitaçóes e pode o convencer de uma, supostamente criada, incapacidade. As PAII vêm oportunizar ao ambiente educacional e aos alunos com deficiências, que algo diferente aconteça. Essas práticas propiciam um despertar das consciências no processo de ensino e aprendizagem para as potencialidades do ser e podem contribuir para a superação de estratégias didáticas que acabam por aprisionar o sujeito a sua deficiência.

As práticas de aprendizagem integradoras e inclusivas nascem como produto da pesquisa de doutorado de Alves (2016), a qual foi gestada a partir da sua experiência frente a suas limitaçóes físicas e sua relação com práticas pedagógicas e com o mundo. Diante das dificuldades vivenciadas, a pesquisadora supracitada, desenvolve formas de agir e se posicionar no mundo, bem como superar os empasses que a vida apresenta. Tais formas unem a ação e a afetividade que dá à luz para diversas potencialidades fluírem no mundo e principalmente no âmbito educacional. De acordo com Pereira Filho (2019) as PAII podem ser compreendidas como possibilidades interventivas existentes na educaçáo e que oportuniza ao ser humano um modo singular de recriar-se, assim como reinventar as coisas frente aos obstáculos encontrados e dá sentido a elas.

Segundo Alves (2016), as PAII tratam-se de práticas que religam o ser humano a si mesmo, ao outro e ao mundo através do "[...] diálogo de tessitura, de respeito, de legitimação do outro e de si mesmo, em que palavras proferidas e as escutas escutadas são feitas pelo prazer de tecer, de comunicar [...]" (ALVES, 2016, p. 69). Estas práticas perpassam pela atitude de fazer o novo de novo, construir descontruindo. Tais aprendizados propiciam ao sujeito um contato com suas potencialidades, dando sentido a elas, validando sua inteireza. Dessa forma é possível aprender o esperado e o inesperado, o previsível e o imprevisível, a imergência e as emergências encontradas na educação e no mundo. 
É válido ressaltar que as PAII se apropriam da palavra integradora pois busca designar com mais ênfase as estratégias que englobem a razão, intuição, imaginação, emoção dos sujeitos de forma multidimensional e multirreferencial. A integração está pautada na agregação, união, na interconexão e propicia a (re) ligaçấo do ser humano consigo, com o outro e com a natureza, o que contribui para que este sinta-se como parte de um todo (ALVES, 2016).

Frente a isso, é possível refletir que as PAII através do olhar e açóes multidimensionais e multissensoriais alcançam o que está para além do observável, do previsto e do esperado. Essas práticas alcançam a subjetividade do sujeito, o que não é possível ver com os olhos, o que não é possível sentir com o tato. Essas estratégias alcançam as emoçōes, o que está oculto, porém presente, a imaginação, a emoção, a sensação, os aspectos humanos de um ser que tem múltiplas dimensóes.

As PAII são fundamentadas pela transdisciplinaridade (NICOLESCU, 1995) e o pensamento complexo (MORIN, 2007) e o pensamento ecossistêmico $^{3}$ (MORAES, 2007). Para desenvolver práticas de aprendizagem integradoras e inclusivas faz-se necessário compreender o processo de formação para além dos conteúdos disciplinares, é preciso ir além, trabalhar com o inesperado de forma transdisciplinar. Para pensar complexamente o processo de aprendizagem é fundamental reconhecer o sujeito nas suas múltiplas dimensôes. Considerar que a dimensão cognitiva é importante na formação do sujeito é fundamental, entretanto, validar que outras dimensōes também são relevantes na sua formação, é enxergá-lo na sua diversidade, na sua multiplicidade, na sua complexidade. Faz-se necessário desenvolver um olhar para a integração do ser, para a sua completude. Nesse sentido, o sujeito inteiro e integrado também ocupa um lugar no mundo, fazendo parte de um ecossistema. É um sujeito produto e produtor do meio em que vive e, portanto, sua formação enquanto ser também perpassa por essa existência. Neste meio, o sujeito consegue aprender e ensinar, (re) criar suas práticas, (re) significar os fenômenos, bem como atribuir sentidos as coisas.

Para Alves (2015) as PAII buscam integrar o ser. Essas práticas têm um "diálogo inter, transdisciplinar, ecossistêmico e complexo que nos permite ir além de nossas gaiolas epistemológicas mentais" (ALVES, 2013, p. 148). Essas estratégias inovadoras permitem o ensinar criativo e a autoria de cada ser. A exemplo disso, Buscaglia (1989) ensina que é possível uma criança conhecer

\footnotetext{
${ }^{3} \mathrm{O}$ pensamento ecossistêmico refere-se a visão de inter-relaçáo dos sistemas existentes no mundo, por exemplo: (sociedade, natureza, cultura, informação) (MORAES, 2007).
} 
o que é uma árvore de forma criativa. Ou seja, em vez de mandar a criança pintar a árvore dessa ou daquela cor, é preciso ir além, é necessário experienciar a árvore, saborear seus frutos, sentir seu cheiro, senti-la por completo. Diante desse contexto, é notório como o autor defende uma forma de ensinar que abraça a experiência do sujeito na interação com os objetos, com o seu meio, juntamente com suas sensaçóes, suas percepçôes, desenvolvendo sua aprendizagem. Nisso, percebe-se a interconexão do sujeito com o seu eu e com o todo interligado. É possível entrever também como as várias dimensóes do ser humano são trabalhadas, e como suas potencialidades são materializadas. Maturana (1997) também aponta as diversas formas de aprender e enfatiza a importância do amor em cada gesto e ação no educar. Ao refletir sobre a posição desses autores é perceptível que oportunizando-se ao aluno maneiras de aprender criativamente, na relação interativa consigo mesmo e com mundo, oportunizando-se também a presença da emoção nessa relação, atribui-se mais sentido ao processo de ensino e aprendizagem. Isso também possibilita o pertencimento do sujeito na construção de sua autoria e sua presença no mundo. Nesse sentido, as práticas de aprendizagens integradoras e inclusivas são ferramentas que viabilizam para que isso aconteça, que o sujeito aprenda de formas criativas e seja autor de sua própria história formativa.

Frente a isso, é perceptível como se faz essencial a leitura do ser humano multidimensional. Para compreender fenômenos humanos e o processo de aprendizagem, é necessário desenvolver um olhar complexo para o todo, considerar suas múltiplas dimensôes e interligaçóes. Nesse sentido, aspectos subjetivos do sujeito como as emoções, a intuição, a espiritualidade e a afetividade precisam ser vistos tal como a fonte de um rio no mundo da aprendizagem. Faz-se necessário encontrar formas disso acontecer, recursos didáticos possíveis de serem utilizados para alcançar uma forma de ensinar que contemple o sujeito de maneira multidimensional. Para Alves (2015) é através da vivência com as práticas de aprendizagens integradoras e inclusivas que os seres humanos conseguem desenvolver a multidimensionalidade de olhares, compreender que a religação do sujeito ao todo se faz na e pela diversidade. Dessa forma, é possível construir um processo de inclusão na educaçáo norteado por um olhar complexo e transdisciplinar.

Para Orrú (2017) a inclusão traz benefícios para todos os alunos, tendo em vista que contribui na compleição de pessoas mais humanizadas, mais solidárias, mais colaborativas. Nesta perspectiva a inclusão requer espaços plurais de aprendizagens e acontece nas entrelinhas ao tecer uma educação para todos, sendo construída por todos os sujeitos e não ordenados 
hierarquicamente (ORRÚ, 2017). Assim, no processo de formação as práticas de aprendizagens integradoras possibilitam a tessitura das relaçôes, a (re) conexão do ser com sua inteireza, propiciando a aprendizagem e contribuindo com o processo de inclusão (ALVES, 2016).

É válido ressaltar ainda que o uso das PAII propiciam ao sujeito uma conscientização quanto a sua condição humana. Tal condição engloba um sujeito de cooperação diante das diversidades, da solidariedade e da amorosidade (ALVES, 2016). Diante desse contexto, é possível perceber que estas práticas se configuram como estratégias que religam o ser humano as suas potencialidades e virtudes, que podem contribuir com a atuação desses sujeitos no processo de inclusão.

Assim sendo, é por via das PAII que é possível ensinar “... a viver humanamente, humanizar o nosso olhar, nosso sentir, nosso pensar” (ALVES, 2016, p. 43). Ainda nesse contexto, é através dessas práticas que se enxerga a esperança de que algum dia possa ocorrer a aceitação mútua das diferenças entre os humanos, bem como a consciência da ligação existente com tudo e todos.

\section{Metodologia}

A pesquisa foi de natureza qualitativa do tipo exploratória por meio da qual se buscou explorar e descrever um objeto pouco estudado que está situado no bojo das relaçóes sociais contemporâneas. Assim, para tentar alcançar o objetivo desse estudo foi necessário coletar dados através da técnica de entrevistas estruturada captadas em áudio por meio de gravador e teve como foco a identificação dos movimentos que esses professores têm realizado no sentido de construírem práticas pedagógicas que favorecessem o processo de inclusão dos sujeitos vinculados a esse curso. Posteriormente, o material foi transcrito e submetido à análise de conteúdo (BARDIN, 1977). Esse movimento foi iluminado pelo arcabouço teórico do pensamento complexo e da transdisciplinaridade.

A partir do arcabouço teórico trabalhado e do objeto de estudo, foram criadas categorias a priori sendo elas: diversidade, ética, transdisciplinaridade, inclusão, integração, multidimensionalidade humana, aprendizagem, práticas integradoras e inclusivas, complexidade humana. Seguindo as etapas da análise de conteúdo, foram construídas categorias emergentes sendo elas: Diversidade humana; Complexidade humana; Diversidades didáticas; Ética e valores humanos; Questóes políticas. Essas categorias serão apresentadas no próximo 
capítulo de forma mais detalhada, onde servirão para discussão e análise dos resultados. A seguir, encontra-se o roteiro das perguntas realizadas nas entrevistas com os sujeitos participantes e a entrevista completa consta nos apêndices deste trabalho.

Quadro 1 - Entrevista

\begin{tabular}{|ll|}
\hline & Roteiro de entrevista realizada com os professores de psicologia da UFAL \\
\hline $1-$ & Você já teve algum aluno de psicologia com alguma deficiência física e/ou intelectual? \\
$2-$ & O que você compreende como inclusão? \\
$3-$ & Quais os valores que você acha importante no seu dia-dia como docente? \\
$4-$ & Quais são as características importantes, na sua prática docente, que você acredita que \\
$5-$ & favorece a inclusáo dos sujeitos? \\
$6-$ & Você compreende que, na sua proposta, você favorece a inclusáo de todos os sujeitos? \\
$7-$ & Quais as açóes que você realiza para incluir os sujeitos com deficiência física e/ou \\
$8-$ & intelectual, na sua prática docente? \\
$9-$ & Como você enxerga as múltiplas dimensôes dos sujeitos? \\
$10-$ & Quais os aspectos, que você considera importantes, para a formação do profissional em \\
$11-$ & psicologia? \\
$12-$ & Quais os movimentos você considera relevantes, no estudante de psicologia, com vistas a \\
$13-$ & favorecer o desempenho acadêmico do mesmo? \\
$14-$ & O que você espera do futuro profissional dos seus alunos hoje? \\
$15-$ & Como você enxerga as possíveis dificuldades existentes, na tentativa de favorecer a \\
$16-$ & inclusáo dos alunos?
\end{tabular}

Fonte: Autora (2019).

\section{Análise e discussão dos resultados}

Realizamos uma entrevista com três participantes individualmente, onde foi possível obter dados para analisar. Após a coleta fizermos a leitura flutuante e, posteriormente, a exploração do material para análise. Neste processo, fizemos a categorização diante das respostas das entrevistadas que resultaram em cinco categorias temáticas: Diversidade humana; Complexidade humana; Diversidades didáticas; Ética e valores humanos; Aspectos políticos. Diante dos conteúdos que mais eram evidenciados no discurso dos sujeitos entrevistados se justificou a escolha dessas categorias.

No decorrer das análises emergiram três subcategorias em cada categoria, exceto a de ética e valores humanos. Com base nas PAII foram 
estabelecidas categorias a priori: diversidade, ética, transdisciplinaridade, inclusão, integração, multidimensionalidade humana, aprendizagem, práticas integradoras e inclusivas, complexidade humana. Essas contribuíram para a discussão das categorias emergentes. A seguir será exposto um quadro com as categorias e subcategorias emergentes criadas a partir da representatividade das respostas dos entrevistados. Posteriormente, será apresentado um recorte das análises de tais categorias e suas respectivas subcategorias à luz do referencial teórico já mencionado. De cada categoria explicitaremos apenas uma subcategoria com uma fala dos sujeitos para consubstanciar a discussão.

Quadro 2 - Categorias Emergentes

\begin{tabular}{|c|c|}
\hline Categoria & Subcategoria \\
\hline 1 Diversidade Humana & $\begin{array}{l}\text { 1.1 Reconhecimento do aluno com deficiência } \\
\text { 1.2 Diálogo e despeito às diversidades } \\
\text { 1.3 Diversidades e diferenças }\end{array}$ \\
\hline 2 Complexidade Humana & $\begin{array}{l}\text { 2.1 Integralidade humana e linguagem } \\
\text { 2.2 Potencialidade humana e afetividade; } \\
\text { 2.3 Escuta sensível, transformaçáo e desenvolvimento pessoal }\end{array}$ \\
\hline $\begin{array}{l}3 \text { Didáticas Inclusivas, Ativas e } \\
\text { Participativas }\end{array}$ & $\begin{array}{l}\text { 3.1 Disponibilidade, Flexibilidade Didática e Criatividade } \\
\text { 3.2 Participaçáo do aluno } \\
\text { 3.3 Metodologias Adaptadas e Ativas }\end{array}$ \\
\hline 4 Ética e Valores humanos & \\
\hline 5 Favorecer à Inclusão & $\begin{array}{l}\text { 5.1 Reconhecimento das dificuldades em favorecer à Inclusáo } \\
\text { 5.2 Formaçáo docente } \\
\text { 5.3 Aspectos políticos }\end{array}$ \\
\hline
\end{tabular}

Fonte: Autora (2020). 


\section{Categoria 1 - Diversidade Humana}

\section{Reconhecimento do aluno com deficiência}

Reconhecer o outro em toda sua completude parte do pressuposto que o ser humano é constituído por diversas dimensões. Para Morin (2005) ao expandir a consciência para enxergar o humano além do que é observável, é possível compreender as diversas formas de ser no mundo. Olhar para o outro e não reconhecer sua plenitude, cega as potencialidades inerentes no sujeito, o que pode subjugar suas habilidades. Nas falas das entrevistadas percebe-se a forma como elas reconhecem o aluno com deficiência o que faz surgir questionamentos a partir da interpretação à luz da teoria da complexidade.

Tive dois alunos com deficiência física (RP.1); Eu só tenho um aluno que é cego (RP.2); ...tenho um aluno de psicologia com deficiência física [...] dois cadeirante [...] e tem também com deficiência visual (RP.3).

A partir do discurso dos sujeitos da pesquisa quanto a sua experiência com alunos com deficiências físicas e/ou intelectuais, nota-se que esses docentes reconhecem as deficiências em seus alunos prioritariamente pelo campo observacional. Isso sugere reflexóes quanto ao conteúdo revelado e o silenciado. Não fica claro como esses docentes compreendem a deficiência, mas é notório que as participantes mencionaram apenas as deficiências possíveis de ver. Entretanto, faz-se importante levantar o seguinte questionamento: Será que não há alunos com outras deficiências que não conseguem ser alcançadas através do olhar, como a deficiência intelectual? E como os professores identificariam isso? Existe o processo de situá-lo no mundo? Tendo em vista que "Conhecer o humano é, antes de mais nada, situá-lo no universo, e não o separar dele” (MORIN, 2011, p. 47) é necessário que haja o (re) conhecimento de cada sujeito nas inúmeras esferas de vida. Em nenhum momento foi mencionado essa dimensão intelectual tampouco, uma outra. Isso abre margem para pensar se essa dimensão é considerada, se existe uma preocupação em atentar-se para isso. E, caso não exista, o docente acaba por limitar o processo de inclusão, tendo em vista que, apenas os alunos com deficiências físicas e visual estão sendo percebidos e aqueles que não tem suas deficiências percebidas ficam afastados desse processo. 


\section{Complexidade Humana \\ Integralidade humana e linguagem}

Para Alves (2016) pensar o ser humano de forma complexa é pensar no sujeito multidimensional, integrado e integrador no qual está interconectado no mundo através da linguagem. De acordo com olhar de Maturana (1997) a linguagem propicia toda realização humana. $\mathrm{O}$ ser humano vivencia um processo de interaçóes recorrentes que emerge a partir da integração entre o sujeito, o meio e a linguagem. Nesse sentido a realização desse indivíduo dependerá dessa linguagem que surge a partir da emoção, da interação desse linguajar com o emocionar. Para esse autor não há como separar emoção e cognição, o sentir e o pensar, o que explica a sua teoria autopoiética.

A autopoiéses defende que o processo de construçáo do conhecimento está conciliado com o dinamismo da vida, no qual ocorre a interação entre o pensar e o sentir. Nesse sentido, a aprendizagem está interligada com as emoçóes, afetividade, pensamentos e a linguagem tem a função de integrar esses elementos (MATURANA, 1997). Diante desse contexto, ao analisar as falas foi perceptível a importância que os docentes atribuem a linguagem na educação inclusiva, como pode ser verificado a seguir:

Agora tem uma questão para mim crucial que é a linguagem né, esse movimento, esse recurso que a pessoa usa para entrar em contato com o outro [...] quando falo a linguagem eu não falo a linguagem oral, porquê nem todo mundo tem essa linguagem, mas essa linguagem que endereça, que vincula a pessoa ao mundo e ao outro, então para mim você não tem dimensões, tem integrado nesta linguagem, nesta função de movimento para interagir, para se relacionar (RP.3).

A fala acima indica um olhar para a linguagem como fundamental na vida do ser humano. Ao enxergá-lo como um ser complexo, inteiro, interligado ao outro e ao mundo, é possível evidenciar a existência de um fenômeno da interdependência, da tessitura comum. Tal fenômeno refere-se a linguagem que interconecta o sujeito ao outro.

A entrevistada menciona que não enxerga dimensóes no ser humano, mas, enxerga-o como um ser integrado na linguagem e no mundo. Essa posição se assemelha com o operador cognitivo da enação (MORIN, 2005) que aborda a relação do sujeito com o mundo, em que ambos são coimbricados. Para isso, é necessário pensar no sujeito constituinte e constituído no mundo, legitimando as relações como fundamentais neste 
processo. Diante da perspectiva do pensamento complexo o humano é integrado no mundo e integralizador neste mesmo mundo. Alves (2016) enfatiza que se tornar inteiro e fazer dessa inteireza parte deste mundo, possibilita ao ser humano construir relaçóes por meio da linguagem.

\section{Didáticas inclusivas, ativas e participativas}

Disponibilidade, flexibilidade didática e criatividade

Esta subcategoria foi criada a partir da atenção dada aos aspectos mencionados no discurso dos entrevistados. A sintonia existente entre a disponibilidade do professor em atender as peculiaridades do seu aluno, a flexibilidade em mudar as didáticas lançando mão da criatividade foram aspectos que sobressaíram nestas falas. Sendo assim, abaixo serão analisados os recortes das falas que alimentam esta percepção e serão discutidas a luz do referencial teórico já apresentado.

Acho que somos todos muito heterogêneos. O que funciona com um não funciona com outro, o que funciona numa turma não funciona na outra turma não funciona. Eu acho que é você está sempre aberto, tentar estar disponível para mudar também, de se adaptar a essa heterogeneidade que é humana (RP.1).

Compreender e tentar atender às diversidades humanas que fazem parte do processo educacional, implica que o professor precisa ter flexibilidade e disponibilidade com as emergências. No recorte acima é possível perceber que o entrevistado entende que sua prática como docente deve ser adaptável e flexível. Essa adaptação advém das peculiaridades existentes em cada ser, em cada sala de aula, em cada forma de ser e estar no mundo.

\section{Ética e Valores Humanos}

Esta subcategoria foi criada pelo destaque que se deu na fala dos entrevistados da pesquisa a respeito da ética, valores humanos e seus aspectos subjacentes. De forma predominante a ética é vista como aspecto fundamental na prática docente e na formação do aluno. Considerar os valores humanos e a ética como sustentáculos para uma prática docente com vistas a inclusão na educação, mostra que o olhar para o processo de ensino e aprendizagem vai 
além das práticas tradicionais de ensino. Podemos verificar abaixo uma fala que nos leva a refletir sobre isso:

Eu acho [...] Valores [...] eu acho que é preciso muita ética, muita compreensão, muita dedicaçáo ao trabalho de docente, muito compromisso com o trabalho da docência (RP.1).

Diante do discurso da entrevistada RP.1, é possível perceber que ela elenca como principais valores de sua atuação docente a Ética, o Compromisso e a Compreensão, o que implica uma permanente autocrítica sobre sua ação pedagógica, com vista a um processo avaliativo permanente a respeito de sua prática inclusiva. Ao tomarmos a categoria da Ética a partir de Morin (2005) podemos pensar na possibilidade da construçáo de uma macrocategoria que se revela em nós de maneira interior, externa e anterior. Trata-se de um elemento interior que precede no humano como um dever, é externa por ser constituída no campo do processo cultural e assim ordena as regras sociais e coletivas e é anterior por ser um regulador civilizatório transgeracionalmente transmitida. Assim em articulação com os processos inclusivos a ética permite sustentar uma concepção de valores humanos que possibilitam o intercruzamento da vida, da cultura e da história humana para além dos processos de ensino.

\section{Categoria 5 - Favorecer à Inclusáo \\ Reconhecimento das dificuldades em favorecer a inclusáo}

Ao falar de inclusão em qualquer nível de ensino, faz-se necessário reconhecer os desafios existentes no universo da educação e refletir sobre as possibilidades de enfrentamento.

No recorte da fala abaixo podemos perceber que há um reconhecimento do professor RP.1 sobre as dificuldades enfrentadas na sua docência. Analisemos a seguir:

Eu acho que para além das dificuldade estruturais que são muitas, estruturais também no sentido de tempo, você precisa de mais tempo para a disponibilidade, de mais tempo para a preparaçáo de aulas, de mais material, enfim, para adaptar as questóes didáticas mesmo [...] a gente vive numa roda viva táo grande, coisas pra fazer de pesquisa e extensão e para você abarcar essa diversidade que a inclusão precisa, você precisa de um tempo de preparação de acesso a material que nem 
sempre a gente tem e eu acho que principalmente a disponibilidade de fazer isso, de estar disposto a dedicar um tempo a mais para esse aluno, adaptar material [...] Estrutural no sentido também de estar disponível para flexibilizar suas práticas (RP.1).

É notório diante da fala que as dificuldades encontradas estão entrelaçadas entre questôes estruturais e disponibilidade de tempo. É importante reconhecer e verbalizar que para o processo de inclusão acontecer é necessário a utilização de recursos adaptados, abertura para a flexibilidade e disponibilidade. Entretanto, tudo isso torna-se insuficiente quando se considera todo um contexto com elementos que dificultam a realização dessas práticas que favorece o processo de inclusão. Esses elementos englobam questóes arquitetônicas para acessibilidade, a falta de materiais para fazer recursos, a sobrecarga de trabalho enfrentada pelos professores, a conjuntura social e política que estamos vivenciando.

\section{Consideraçóes finais}

Pensar em inclusão na educação, especialmente no ensino superior, acarretam desafios rotineiros como pensar complexamente o ser humano e enxergá-lo para além de suas deficiências e limitaçóes. Inquietações voltadas para práticas pedagógicas que superem o pensamento reducionista do humano e proporcione uma formação que religue todos os saberes se fazem necessárias, para que seja possível um trabalho transdisciplinar e alcance a complexidade.

Ao aprofundar nas leituras sobre o pensamento complexo e a transdisciplinaridade, conseguimos ver o quanto uma se faz necessário para a outra. O pensamento complexo possibilita que o trabalho do professor ocorra de forma transdisciplinar e o contexto da educação passa a incluir aquele que antes não era visto em sua complexidade.

Nesta investigação pudemos entrar em contato com profissionais que estão atuando no ensino superior e que desenvolvem práticas pedagógicas na tentativa de favorecer a inclusão.

Foi pertinente observar que os resultados coletados alcançaram os objetivos desta pesquisa. Tendo em vista que o objetivo geral foi investigar as práticas pedagógicas desenvolvidas no curso de psicologia ofertado na Universidade Federal de Alagoas - UFAL e suas aproximaçóes com as práticas integradoras e inclusivas que contribuem para um processo inclusivo que 
compreenda o sujeito para além de sua dimensão cognitiva, conseguimos nos apropriar do que vem sendo realizado pelos docentes deste curso.

Toda prática pedagógica que contemple as diversidades se aproxima das PAII, tendo em vista que se ancora nos princípios da complexidade e da transdisciplinaridade. Uma prática docente que se preocupa em contemplar a imensidão que há em cada ser, conjuga com os processos educativos que se alimentam das bases epistemológicas do pensamento complexo. $\mathrm{Na}$ fala dos participantes nota-se a tentativa de abarcar essas diversidades e isso nos revela uma forma de lidar com o inesperado. Ao adentrar em uma sala de aula, sabemos que iremos encontrar alunos, mas não presumimos as possíveis limitaçóes que poderão se apresentar em cada um deles. Diante disso saber lidar com o inesperado, com as emergências, é percorrer pelas trilhas da complexidade e da transdisciplinaridade. Assumir o compromisso de ensinar ao outro perante suas diversidades é compartilhar dos diversos níveis de realidade de cada ser na construção da aprendizagem e na teia do conhecimento.

No discurso dos docentes observou-se uma característica que enfatiza a compreensão da inclusão como uma proposta de educação que considera de fato a diversidade. Nessa proposta é necessário "construir uma docência que religue os diversos saberes em diferentes dimensóes da vida, percebendo a complexidade das relaçóes existentes entre as partes e o todo..." (BEHRENS; PRIGOL, 2019, p. 72). Nesse sentido, os constructos para uma educação que perceba essa complexidade do sujeito e das relaçóes inerentes no processo educacional, perpassa pelo fazer profissional do professor. Tal fazer, precisa superar as práticas tradicionais de ensino e considerar as diversidades dos saberes, bem como a multidimensionalidade do ser humano. Os diversos saberes entrelaçados na construção do conhecimento possibilitam a construção de algo que está nas disciplinas, entre elas e para além delas (NICOLESCU, 2008).

Os desenlaces da pesquisa em tela corroboraram para a identificação sobre o que o curso de psicologia da UFAL vem proporcionado aos seus alunos com deficiências, através das práticas pedagógicas de seus professores. É notório que movimentos na tentativa de incluir os graduandos em psicologia nesta Universidade estão sendo realizados, mesmo que parcialmente, em diversas perspectivas e que alguns destes vem se aproximando das práticas integradoras e inclusivas (ALVES, 2016). Ao perceber que professores estão se dedicando a atender o seu aluno para além de dificuldades físicas e/ou cognitivas, é possível se estabelecer um diálogo genuíno com a teoria da complexidade (MORIN, 2007). 
Salienta-se ainda que esta pesquisa permitiu identificar açóes que impulsionaram a aprendizagem do aluno, por parte destes docentes entrevistados, o que contribui com a seguridade do direito a educação, a aprendizagem do cidadão. No sentido de que incluir é também assegurar o outro frente aos seus direitos, desenvolver práticas de aprendizagens que contemple a inteireza do ser como explana Alves (2016), objetivando a aprendizagem, possibilita a esse aluno um desfrutar do seu direito. Nesse sentido, o direito a educação é fator fundamental para impulsionar e garantir justiça social.

$\mathrm{Na}$ análise realizada foi perceptível refletir que, apesar do olhar dos professores para o aluno com deficiência estar mais complexo, ainda precisa ser ampliado. Essa inferência é colocada pois, em um primeiro momento, a deficiência visível ao olhar, ainda se sobressaiu, fato que pode nos apontar a necessidade de um trabalho transdisciplinar. Tal fato endossa ainda mais a necessidade de desenvolvemos mais estudos voltados para o tema de inclusão da educação na perspectiva do pensamento complexo e na transdisciplinaridade.

Além disso, as pesquisas sobre Práticas de Aprendizagem Integradoras na perspectiva da complexidade e transdisciplinaridade ainda é bem escassa, o que nos faz (re)lembrar a possibilidade de ampliar nossos estudos e investigaçóes acerca destas temáticas. Não obstante, apontamos ainda que, apesar do universo da amostra de pesquisa serem apenas 3 sujeitos, o material colhido nos relatos mostra o que os alunos de psicologia, com ou sem deficiências, estão tendo contato e qualidade nas ações pedagógicas. Isso incentiva ainda mais a desenvolver novas pesquisas nesse campo e ampliar o tamanho da amostra para investigaçóes em outros cursos e Universidades.

\section{Referências}

ALVES, M. D. F. Cenários e estratégias de aprendizagem integradoras: a complexidade e transdisciplinaridade legitimando a diversidade e o "habitar humano". Revista Terceiro Incluido, Goiana, v. 5, n. 1, p. 315-338, jan/jun, 2015. DOI: 10.5216/teri.v5i1.36361.

ALVES, M. D. F. Construindo cenários e estratégias de aprendizagem integradoras (inclusivas). Orientador: José Armando Valente. 276 f. 2013. Tese (Doutorado em Educação) - Pontifícia Universidade Católica de São Paulo, São Paulo, 2013. p. 276. 
ALVES, M. D. F. Práticas de aprendizagem integradoras e inclusivas: autoconhecimento e motivação. Rio de Janeiro: Wak Editora, 2016. ISBN 978-85-7854372-3

BARDIN, L. Análise de conteúdo. Lisboa: Ediçôes 70, 1977. ISBN: 972-440898-1.

BEHRENS, M. A.; PRIGOL; E. L. Prática docente: das teorias críticas à teoria da complexidade. In: SÁ, R. A.; BEHRENS, M. A. (org.). Teoria da complexidade: contribuiçóes epistemológicas e metodológicas para uma pedagogia complexa. Curitiba: Appris, 2019. ISBN: 978-85-473-3564-9.

BUSCAGLIA, L. F. Amor. Rio de Janeiro: Record, 1989.

MATURANA, H. A ontologia da realidade. Belo Horizonte: Editora da UFMG, 1997.

MORAES, M. C. A formação do educador a partir da complexidade e da transdisciplinaridade. Diálogo Educacional, Curitiba, v. 7, n. 22, p.13-38, set./dez. 2007. ISSN: 1518-3483.

MORIN, E. Ensinar a viver: manifesto para mudar a educação. Porto Alegre: Sullina, 2015. ISBN: 9788520507421.

MORIN, E. Introdução ao pensamento complexo. Tradução Eliane Lisboa. 3. ed. Porto Alegre: Sulina, 2007. ISBN: 9788520505984.

MORIN, E. $O$ método 1: a natureza da natureza. 2. ed. Porto Alegre: Sulina, 2005. ISBN: 8520503071.

MORIN, E. Os sete saberes necessários à educação do futuro. 2. ed. São Paulo: Cortez: Brasília, DF: Cortez: UNESCO, 2011. ISBN: 9788524917547.

NICOLESCU, B. Ciência, sentido e evolução: a osmologia de Jacob Boehme. São Paulo: Attar, 1995.

NICOLESCU, B. O manifesto da transdisciplinaridade. São Paulo: Trion, 2008. ISBN10:8585464224.

ORRÚ, S. E. O re-inventar da inclusão: os desafios da diferença no processo de ensinar e aprender. Petrópolis: Vozes, 2017. ISBN: 9788532653314.

PEREIRA FILHO, A. D. As múltiplas dimensóes do fazer pedagógico criativo de uma escola alagoana: contribuiçóes no sentido da construção de um ambiente inclusivo. 2019. 148 f. Orientadora Maria Dolores Fortes Alves. Dissertação 
(Mestrado em Educação) - Universidade Federal de Alagoas, Maceió, 2019. p. 149.

SOARES. I. N. L. Práticas integradoras no ensino superior: análise das experiências de inclusão nos cursos de psicologia na perspectiva da teoria da complexidade e da transdisciplinaridade. 2020. Dissertação (Mestrado em Educação) - Universidade Federal de Alagoas, Maceió, AL, 2020.

Recebido em: 22 set. 2020

Aceito em: 13 dez. 2020 